\title{
Anatomical pathways for auditory memory in primates
}

\author{
Monica M. Munoz-Lopez*, Alicia Mohedano-Moriano and Ricardo Insausti
}

Human Neuroanatomy Laboratory, Department of Health Sciences, School of Medicine, University of Castilla-La Mancha, Albacete, Spain

\section{Edited by:}

Enrique Saldaña, Universidad de

Salamanca, Spain

\section{Reviewed by:}

Jon H. Kaas, Vanderbilt University, USA

Marcello G. Rosa, Monash University,

Australia

\section{*Correspondence}

Monica M. Munoz-Lopez, Human Neuroanatomy Laboratory,

Department of Health Sciences,

School of Medicine, University of

Castilla-La Mancha, Ave. Almansa,

14,02006 Albacete, Spain.

e-mail:monica.munozlopez@uclm.es
Episodic memory or the ability to store context-rich information about everyday events depends on the hippocampal formation (entorhinal cortex, subiculum, presubiculum, parasubiculum, hippocampus proper, and dentate gyrus). A substantial amount of behavioral-lesion and anatomical studies have contributed to our understanding of the organization of how visual stimuli are retained in episodic memory. However, whether auditory memory is organized similarly is still unclear. One hypothesis is that, like the "visual ventral stream" for which the connections of the inferior temporal gyrus with the perirhinal cortex are necessary for visual recognition in monkeys, direct connections between the auditory association areas of the superior temporal gyrus and the hippocampal formation and with the parahippocampal region (temporal pole, perhirinal, and posterior parahippocampal cortices) might also underlie recognition memory for sounds. Alternatively, the anatomical organization of memory could be different in audition. This alternative "indirect stream" hypothesis posits that, unlike the visual association cortex, the majority of auditory information makes one or more synapses in intermediate, polymodal areas, where they may integrate information from other sensory modalities, before reaching the medial temporal memory system. This review considers anatomical studies that can support either one or both hypotheses - focusing on anatomical studies on the primate brain, primarily in macaque monkeys, that have reported not only direct auditory association connections with medial temporal areas, but, importantly, also possible indirect pathways for auditory information to reach the medial temporal lobe memory system.

Keywords: episodic memory, auditory memory, non-human primate, neuroanatomy, medial temporal cortex, cortical input, subcortical input

\begin{abstract}
Abbreviations: 7a, area 7a of the inferior parietal cortex; 23, area 23 (Brodmann, 1909); 24, area 24 (Brodmann, 1909); 25, area 25 (Brodmann, 1909); 32, area 32 (Brodmann, 1909); 35, area 35 of the perirhinal cortex (Brodmann, 1909); 36r, rostral division of area 36 of the perirhinal cortex (Insausti et al., 1987a); 36c, caudal division of area 36 of the perirhinal cortex (Insausti et al., 1987a); 36pl, lateral portion of the temporal pole (Insausti et al., 1987a,b); 36pm, medial portion of the temporal pole (Insausti et al., 1987a,b) 36p-dm, dorsal division of the temporal pole (Macaca mulatta); 36p-vm, ventral medial divisions of the temporal pole (Macaca mulatta); 38DL, dorsal lateral division of the temporal pole; $38 \mathrm{VL}$, ventral lateral division of the temporal pole; A, amygdala; A1, area A1 (Kaas and Hackett, 2000); AL, area AL (Kaas and Hackett, 2000); amts, anterior middle temporal sulcus; cc, corpus callosum; cis, cingulate sulcus; CA1, field CA1 of the hippocampus; $\mathrm{CA} 2$, field $\mathrm{CA} 2$ of the hippocampus; $\mathrm{CA} 3$, field CA3 of the hippocampus; CL, area CL (Kaas and Hackett, 2000); CM, area CM (Kaas and Hackett, 2000); DM, area DM (Kaas and Hackett, 2000); EC, entorhinal cortex; $\mathrm{E}_{C}$ caudal subfield of EC (Amaral et al., 1987); $\mathrm{E}_{\mathrm{CL}}$ caudal limiting subfield of EC (Amaral et al., 1987); $\mathrm{E}_{\mathrm{b}}$ intermediate subfield of EC (Amaral et al., 1987); $\mathrm{E}_{\mathrm{IC}}$ lateral caudal subfield of EC'(Amaral et al., 1987); $\mathrm{E}_{\mathrm{Lr},}$ lateral rostral subfield of EC (Amaral et al., 1987); $E_{0}$ olfactory subfield of EC (Amaral et al., 1987); $E_{R}$ rostral subfield of EC (Amaral et al., 1987); DG, dentate gyrus; CA1, area CA1 of the hippocampus; Ia, insula; IPa, area IPa of Seltzer and Pandya $(1978,1989)$; Ls, lateral sulcus; MM, area MM (Kaas and Hackett, 2000); PaI, Parainsular cortex; PGa, area PGa of Seltzer and Pandya $(1978,1989)$; pmts, posterior medial temporal sulcus; Pul, Pulvinar; R, area R (Kaas and Hackett, 2000); RM, area RM (Kaas and Hackett, 2000); rs, rhinal sulcus; RT, area RT (Kaas and Hackett, 2000); RTL, area RTL (Kaas and Hackett, 2000); RTM, area RTM (Kaas and Hackett, 2000); STG, superior temporal gyrus; STGf, fundus of the STG (Insausti et al., 1987a); STGi, intermediate division of the STG (Insausti et al., 1987a); STGm, medial division of the STG (Insausti et al., 1987a); STGo, opercular division of the STG (Insausti et al., 1987a); STGp, posterior division of the STG (Insausti et al., 1987a); STGr, radial division of the STG (Insausti et al., 1987a); sts, superior temporal sulcus; Sub, subiculum; TAa of Seltzer and Pandya $(1978,1989) ;$ TE, area TE of Von Bonin and Bailey (1947); TF, area TF of Von Bonin and Bailey (1947); TFl, lateral division of area TF (Insausti et al., 1987a); TFm, lateral division of area TF (Insausti et al., 1987a); TH, area TH
\end{abstract}

of Von Bonin and Bailey (1947); Thal, thalamus; THc, caudal division of area TH (Insausti et al., 1987a); THr, rostral division of area TH (Insausti et al., 1987a); TP, temporal pole; TPO of Seltzer and Pandya (1978, 1989); Tpt, area Tpt of Seltzer and Pandya (1978, 1989); Ts1, area Ts1 of Seltzer and Pandya (1978, 1989); Ts2, area Ts2 of Seltzer and Pandya (1978, 1989); Ts3, area Ts3 of Seltzer and Pandya $(1978,1989)$

\section{COGNITIVE NEUROSCIENCE OF EPISODIC MEMORY}

The aim of this review is to consider the anatomical substrate of auditory memory. We explore two possible questions. First, in analogy with the classic view of visual processing (Mishkin and Ungerleider, 1982): Is the flow of information in the auditory domain relatively direct and corresponds to a straightforward "auditory ventral stream" leading to memory? Or, alternatively: Does auditory information take a more indirect route, with additional synaptic steps, and this makes possible added features of auditory perceptual processing and the integration of auditory information with other sensory modalities, emotion, and motivation?

Anatomical studies cannot, on their own, differentiate these two views; they do, however, reveal both opportunities and constraints on the manner by which sensory information reaches brain regions involved in memory processing (Figure 1).

\section{THE NATURE OF EPISODIC MEMORY}

Episodic memory refers to the ability to store information about everyday events and encompasses a complex system of hippocampocortical and hippocampo-subcortical connections (Aggleton and Brown, 1999; see Figure 1 in Munoz and Morris, 2009). Unlike other 


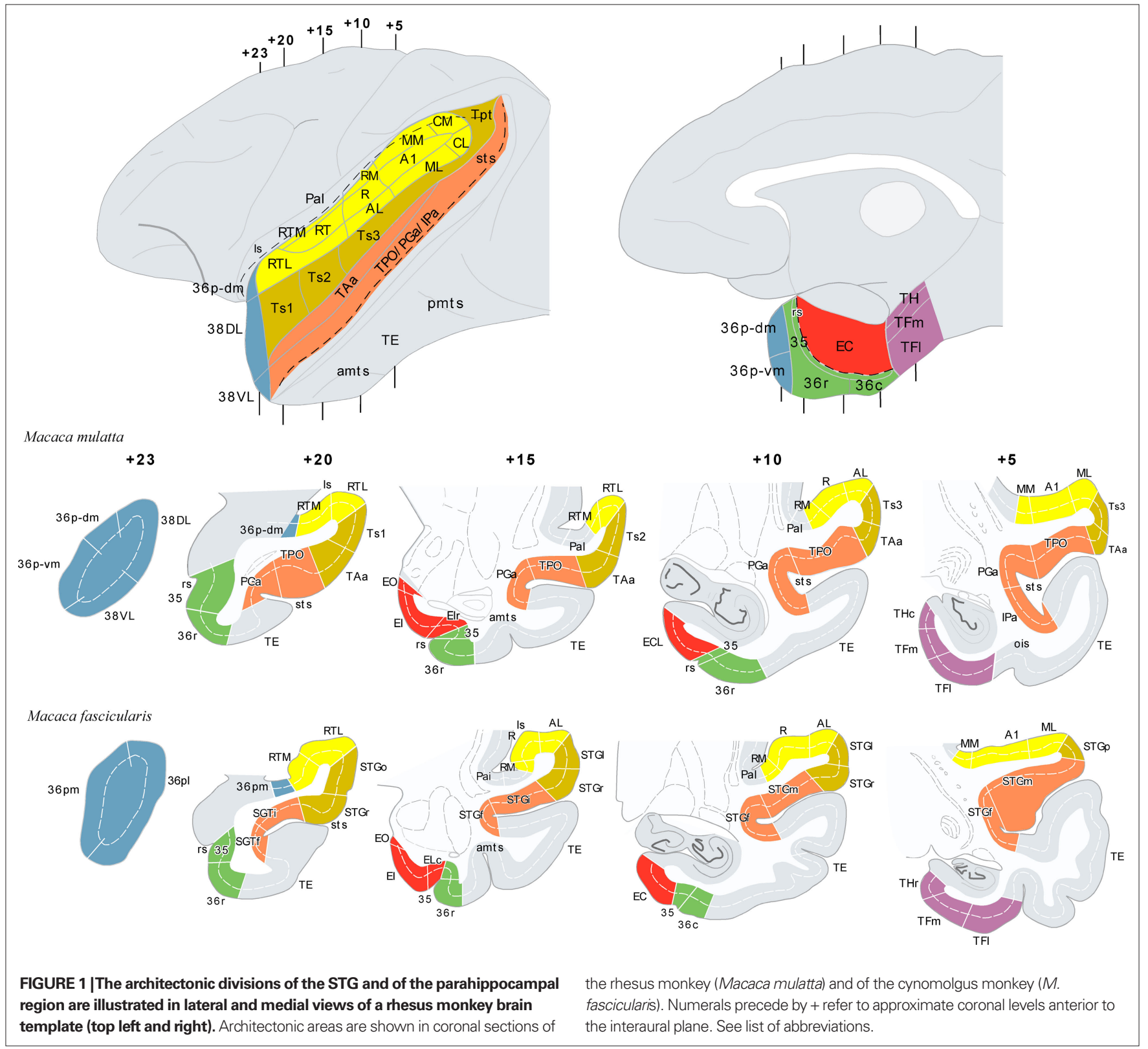

types of memory, as habits or motor skill learning, episodic memory involves the long-term storage, recollection, and retrieval of the "what, where, and when" of everyday events, and yet requires no training. In fact, in contrast to the effortful nature of skill learning, encoding of episodic memory is most often automatic or incidental, whereas retrieval requires conscious effort. This memory system allows us to process and remember information received via different sensory modalities, including the auditory domain. Using it, we can remember, for example, our past holidays, the flavor of our grandmother's cake, the voice of our friends when they phone us, or the sound of our own car.

Episodic memory has been attributed almost exclusively to humans (Suddendorf and Corballis, 1997; Tulving, 2004). However, as the relevant anatomical structures and their connections are shared with other animal species as old phylogenetically as the hedgehog, it is generally assumed that some features of the memory system mediated by them are also shared, even if in more rudimentary form
(Insausti, 1993; Burwell et al., 1995). To stress the differences across species, however, the term "episodic-like" memory has been used for monkeys and rodents (see review in Munoz and Morris, 2009). This is relevant in the context of auditory memory, as humans are unique in having communication through language and the auditory memory system may differ significantly from the non-human primate system for this reason. It is interesting that the anatomical organization of memory in both species may tell us something about the evolution of language and communication.

\section{DEVELOPMENT OF BEHAVIORAL TASKS FOR LESION STUDIES IN ANIMALS}

One of the challenges in animal research has been to design behavioral tasks that are as close as possible to the episodic memory tests used in neuropsychological assessment with humans. Such tasks are critical to study the anatomical and functional organization 
of episodic-like memory in animals. In non-human primates and rodents, episodic memory is often evaluated using trial-unique tasks in which animals have to remember a specific stimulus during a single trial. Each trial requires memory of a different object or image, in a similar way that we experience unique events in everyday life. There is a wide breadth of fascinating tasks, but to describe all of them here would exceed the aim of this review. We summarize one of the critical paradigms from which many different variants have emerged - namely a test of recognition memory. Remembering that you have seen/heard someone or something before is a critical component of episodic memory.

The recognition paradigm extensively used in the study of visual memory is the delayed non-matching to sample task (DNMS). Each trial in this type of task consists in a sample phase where the animal familiarizes with an item (visual, tactile, or more recently, auditory) and, after a variable delay, a choice phase in which the familiar item is presented again but this time paired with a novel one. Reward is delivered only if the animal chooses the novel item of the two, and so on. The delayed matching to sample task (DMS) is exactly the same, except that the animal is rewarded for choosing the familiar rather than the novel item (and in general is slightly harder). Whereas this type of tasks detect reliably the memory impairment due to perirhinal lesions in animals, variants of this task that involve object-context or object-object associations are more sensitive to hippocampal and entorhinal cortex (EC) lesions. In studies of auditory memory, equivalents of DNMS and DMS have been developed but because two sounds cannot be presented simultaneously in the choice phase without confusion, a sequential protocol originally developed by Konorski (1959) in Poland is adopted using a Go-No Go procedure (Fritz et al., 2005; Wright, 2007).

Back in the seventies, one of the pioneering memory studies in monkeys showed that only lesions that include the hippocampus, amygdala, and the adjacent entorhinal and posterior parahippocampal cortices impaired memory in a visual version of the DNMS task (Mishkin, 1978) in a similar way to humans (Scoville and Milner, 1957). A critical finding was that the lesions only caused memory impairment at long delays, while performance at short delays was normal, suggesting intact perception and working memory, but impaired long-term memory. This seminal study paved the way for detailed use of the DNMS task and its auditory variants to study recognition memory.

\section{THE PERIRHINAL AND POSTERIOR PARAHIPPOCAMPAL CORTICES AND MEMORY}

Research since then has shown that amongst the areas included in the original lesion (Mishkin, 1978), EC (area 28 of Brodmann, 1909) and perirhinal cortex (Brodmann's areas 35 and 36) are critical for visual recognition in DNMS tasks in non-human primates (Meunier et al., 1993). The memory deficit observed when these structures are lesioned is delayed-dependent and as severe as that observed in Mishkin's original study.

We now know from retrograde tract tracing studies that the perirhinal cortex receives the majority of its input from visual areas in the inferior temporal cortex (Suzuki and Amaral, 1994a) and sends this information to EC (Insausti et al., 1987a; Suzuki and Amaral, 1994b), from where the information is relayed on to the hippocampus (Witter and Amaral, 1991). A series of connections within the hippocampus characterized by being unidirectional are followed by hippocampal return projections to the cortex primarily via EC, but also directly to the perirhinal cortex (Insausti and Munoz, 2001; Lavenex et al., 2002; Witter and Wouterlood, 2002; Munoz and Insausti, 2005). These connections are thought to be critical for the encoding and long-term consolidation of visual recognition memory.

These neuroanatomical studies reveal the main flow of information underlying visual recognition, but one of the central features of episodic memory is that our memories of events are formed by information received via different sensory modalities (olfactory, somatosensory, auditory as well as visual) and, consequently, episodic memory is often said to be multimodal. Neuroanatomical tract-tracing studies show that, although some sensory-specific information reaches the medial temporal cortex directly (primarily olfactory and visual, as well as, although to a lesser extent, somatosensory and auditory), the great bulk of incoming connections originate in polymodal areas of the neocortex (see review in Mohedano-Moriano et al., 2007) providing our episodic memories with rich, complex contextual information.

\section{WHAT IS DIFFERENT ABOUT AUDITORY MEMORY?}

The possibility of multimodal inputs to the episodic-like memory system raises the question of how well matched is the picture emerging from anatomical and behavioral-lesion studies. To address this question, one study showed that lesions including areas 35 and 36 of the perirhinal cortex and the posterior parahippocampal cortex (areas TH and TF of Von Bonin and Bailey, 1947) impaired not only visual memory, but also tactile memory (Suzuki et al., 1993). This was established by conducting the sample and choice phases of the DNMS task in the dark.

At about the same time, an anatomical study showed that a higher order somatosensory area in the granular insular cortex sends projections directly to area 35 of the perirhinal cortex, and suggested that this pathway might be one direct link between the somatosensory and limbic systems (Schneider et al., 1993). This finding led naturally to the idea that this pathway could be critical for the long-term storage of tactile information. Area 35 of the perirhinal cortex also projects heavily to EC (Insausti et al., 1987a), and therefore information coming from area 35 forms part of the hippocampal-cortical loop (Witter and Amaral, 1991).

It appeared, then, that the perirhinal cortex mediates the storage of information in a multimodal way and hence satisfies one of the critical features of episodic memory. The perirhinal cortex became therefore one of the best candidate areas for episodic-like memory in non-human primates. There are important subtleties to this assertion such as whether the perirhinal cortex is involved in familiarity and the hippocampus is recollection (Brown and Aggleton, 2001; Yonelinas, 2002), but discussion about this subject would again exceed the scope of this review (but see Table $\mathbf{1}$ ).

Does auditory memory store in the same way as in the visual and somatosensory modalities? Are perirhinal and entorhinal cortices necessary for the formation of auditory memory as they are for visual and tactile memory? It is clear that auditory memory depends on medial temporal areas in humans (Prisko, 1963; Squire and Zola-Morgan, 1991), but work on non-human primates indicates that separate lesions of the hippocampus, of the perirhinal plus entorhinal cortex, or of the posterior parahippocampal cortex each fail to impair auditory recognition memory in a Konorski DMS 
Why is more difficult for monkeys to hold in mind auditory information than visual? Do humans have also more difficulties to store auditory information compared to visual?

Medial frontal cortex, especially area 25, is part of the limbic system that is associated with episodic memory. Is this area also important for auditory memory in primates and humans?

Is there an analogue of the perirhinal cortex important for auditory recognition memory?

Anterior cingulate area 24, prelimbic area 32, and area 25 of the infralimbic cortex may be involved in the production of monkey calls. What is their role in auditory processing?

Are motor patterns, such as those related with the articulation of sounds, important for auditory memory?

In monkeys, the dorsal part of the temporal pole receives its major input from the most rostral part of the superior temporal gyrus, but it also receives afferents from multimodal areas. What is the nature of its involvement in the processing of monkey calls?

What areas the similarities and differences of the auditory processing areas in humans and non-human primates?

What is the role of the amygdalar connections with hippocampal formation and the superior temporal gyrus? And how do they contribute to auditory memory?

task (Fritz et al., 2005). In fact, it is especially difficult for monkeys to hold auditory stimuli in memory for a long enough period of time to be considered outside the timeframe of working memory (Fritz et al., 2005). Furthermore, Fritz et al. (2005) reported that the performance of control monkeys in an auditory DMS task is as poor as monkeys with perirhinal cortex lesions in a visual version of a similar task, suggesting that there may be major differences between auditory and visual memory. The question then is that the delayed-dependent memory impairment seen for vision and touch is difficult to observe in audition - the control subjects showing too much forgetting over time to observe the impact of perirhinal cortex lesions. This immediately raised the possibility of a key difference between humans and non-human primates that, if valid, would be of interest in language research.

However, medial temporal lobe resections, that leave working memory intact in vision in human and non-human primates, critically impair this type of short-term memory in audition (Fritz et al., 2005). A possible explanation for this paradoxical finding comes from a combined lesion and tract tracing study showing that medial temporal removals inadvertently disconnect the rostral part of the superior temporal gyrus (STG) from frontal cortex and thalamus (Munoz et al., 2009). It seems, therefore, that humans and non-human primates may not be so different, but we are left with a puzzle about why auditory memory, as usually tested in the DMS, is so poor in macaques. However, the sounds used as stimuli in the tasks may be a critical variable in solving this puzzle, as suggested by a recent behavioral study (Ng et al., 2009). This study reported significant improvement in the performance of rhesus monkeys in a Go/No-Go DMS task when using species-specific vocalizations as stimuli, compared with non-vocalization sound types (Ng et al., 2009).

To better understand the anatomical organization of auditory memory we consider here a number of major tract tracing studies in the non-human primate brain. These studies reveal evidence for direct (monosynaptic) and indirect connections (two synapses) that finally link the STG with the medial temporal lobe memory system, comprising the hippocampal formation (dentate gyrus, hippocampal fields CA1-3, subiculum, presubiculum, parasubiculum, and EC), and the parahippocampal region (temporal pole, areas 35 and 36 of the perirhinal cortex, and the posterior parahippocampal cortex areas TH and TF of Von Bonin and Bailey, 1947).

\section{ANATOMICAL PATHWAYS FOR AUDITORY MEMORY}

Like in vision or touch, direct connections of the auditory cortex with the medial temporal cortex may be critical for the long-term storage of auditory information (Engelien et al., 2000). A better understanding of the auditory cortex anatomical organization may, therefore, contribute to clarify whether memory function is different in audition as compared with the visual and tactile modalities.

\section{ARCHITECTONIC DIVISIONS OF THE STG AND MEDIAL TEMPORAL CORTEX}

The amalgam of architectonic divisions comprising the STG and the medial temporal cortex; areas which interaction might be critical for the storage of auditory information are shown in Figure 1. The neuroanatomy of these areas has been primarily studied in two species of non-human primates, rhesus (Macaca mulatta) and cynomolgus monkeys (Macaca fascicularis). They are largely comparable, although there are subtle differences between them in the architectonic organization. The coronal sections shown in Figure 1 illustrate some of the differences and similarities.

In rhesus monkeys, the STG was described in depth by Pandya et al. (Pandya and Sanides, 1973; Seltzer and Pandya, 1978, 1989) and we have adopted their nomenclature with some modifications. One modification is in relation with the temporal pole (TP), divided here (Figure 1) in four subareas: two in the medial surface (36p-dm and $36 \mathrm{p}-\mathrm{vm}$ ), with similar architecture to area 36 of the perirhinal cortex - and corresponding to area $36 \mathrm{pm}$ in the M. fascicularis (Insausti et al., 1987a) -; and two in the lateral surface (38DL, 38VL), which resemble the architectonics of the adjacent six-layered cortex of the superior and inferior temporal gyri, respectively. These latter divisions have not yet been recognized in the $M$. fascicularis - and corresponding to area 36pl in the M. fascicularis (Insausti et al., 1987a).

In the M. fascicularis, we have used the cytoarchitectonic divisions of the STG and TP described by Insausti et al. (1987a). As Figure 1 illustrates two subareas have been described in the TP in this species and they are referred as $36 \mathrm{pl}$ and $36 \mathrm{pm}$ as they resemble the architectonic organization of area 36 of the perirhinal cortex (Insausti et al., 1987a).

The cytoarchitectonic areas RTL, RT, and RTM, as defined by Kaas and Hackett (2000) can be found in both species for the rostral portion of the supratemporal plane (Kaas and Hackett, 2000), which lies in the ventral bank of the lateral sulcus and differs 
cytoarchitectonically from areas Ts1-3/STGo,l,f,p on the adjacent lateral convexity of the rostral part of STG. The remaining auditory core and belt areas (i.e. A1/R, AL, ML, MM, CL, and CM), located caudally in the superior temporal plane, were delineated according to Kaas and Hackett (2000). The cytoarchitectonic subdivisions of the entorhinal, perirhinal, and posterior parahippocampal cortices of Amaral et al. (1987) and Suzuki and Amaral (1994b) were also used for both species.

\section{DIRECT INPUT FROM STG TO MEDIAL TEMPORAL CORTEX}

Core (primary) and belt (secondary) areas of the auditory cortex in monkeys are characterized by a high density of reciprocal corticocortical connections (Hackett et al., 1998). Connections between belt and parabelt (tertiary) areas of the auditory cortex are also dense, but less well understood. Although rostral and caudal belt areas send projections to prefrontal cortex in rhesus (Romanski et al., 1999a,b) and marmoset monkeys (Roberts et al., 2007), a large proportion of long cortical connections with frontal, temporal, insular, and parietal areas appear to originate primarily in the parabelt areas. In contrast, to parabelt areas, medial temporal cortex connections with core and belt areas have not been reported in the literature so far. The most direct, but not necessarily densest afferent auditory projections to the medial temporal cortex, arise in the lateral parabelt areas of the auditory cortex (see Figure 3 in Amaral et al., 1983).

Apart from the better understood core and belt areas of the auditory cortex (Hackett, 2010), the functional properties of further auditory downstream areas of the STG are only beginning to be revealed by functional imaging studies in rhesus monkeys (Tian et al., 2001; Poremba et al., 2003; Gil-da-Costa et al., 2004, 2006; Poremba et al., 2004; Petkov et al., 2008). However, the neurophysiological features of neurons in the different architectonic areas of the parabelt and areas located just rostral to them, such as the anterior superior temporal plane and the TP, are less known. As a consequence, it is difficult to understand the type of information that is sent to the medial temporal cortex from the STG.

The study by Romanski et al. (1999a) revealed that whereas neurons in the anterior lateral belt show selective responses to particular features of auditory stimuli, neurons in caudal lateral belt have preferential responses to sound location and have different patterns of connections with the frontal cortex. The anterior lateral belt projects to the ventral frontal cortex, whereas the caudal lateral belt is connected with more dorsal aspects of the prefrontal cortex (Romanski et al., 1999b). This suggested that there might be, like in vision, "what" and "where" pathways in the auditory cortex; with the rostral part of the STG as the "what" pathway concerned with the identification of specific features of sounds. In line with this, a recent study showed that the anterior part of the superior temporal plane contains an area that responds specifically to monkey conspecific calls (Petkov et al., 2008). Neurons with species-specific calls have also been found in this area (Kikuchi et al., 2006). Another key area in the auditory ventral stream is the TP, but there is a section dedicated to this question later on in this review.

\section{Entorhinal cortex}

Evidence for the rostral STG projection to EC comes primarily from two retrograde tracer studies. The first one, having placed retrograde tracer injections in EC (Amaral et al., 1983), showed that the auditory input to the lateral EC (subfields $E_{R}$, $\mathrm{E}_{\mathrm{Lr}}$, rostral $\mathrm{E}_{\mathrm{I}}$ ) receives projections from the gyral surface of the STG. This projecting area in the STG extends from the tip of the TP to the rostral part of the lateral geniculate nucleus, a distance of approximately $10 \mathrm{~mm}$ in the M. fascicularis. This extent comprises an area that includes caudally the rostral part of the lateral parabelt of the auditory association cortex (area Ts3, see Figure 3 in Amaral et al., 1983). EC also receives projections from the opercular part of the STG (area TAa, Insausti and Amaral, 2008). However, in the study of Amaral et al. (1983), the authors stressed that not all the regions of the STG project equally heavily to EC; in fact, the multimodal area of the dorsal bank of the superior temporal sulcus (area TPO) consistently contained the largest number of retrogradely labeled cells. Amaral et al. (1983), in their report showed that the projection from the STG to EC was organized topographically; so lateral aspects of the STG (areas Ts1-Ts3 and TAa) project to lateral EC (subfields $E_{R}, E_{L R}$, and $E_{I}$ ), while more medial or proximal aspects of the STG (area TPO) project to intermediate and caudal levels of EC. This results were confirmed in a latter study concerned with the cortical afferents to EC (Insausti et al., 1987a), which showed additionally that EC receives information from diverse polysensory processing areas of the cerebral cortex, including agranular insula, orbitofrontal, and medial regions of the frontal cortex, retrosplenial cortex, inferior parietal cortex, TP, perirhinal, and posterior parahippocampal cortices (Insausti et al., 1987a; Insausti and Amaral, 2008).

\section{Perirhinal and posterior parahippocampal cortex}

Perirhinal and posterior parahippocampal cortices receive their densest input from higher order processing visual areas TE and TEO of the inferior temporal cortex, and the rest from multiple polymodal processing areas of the neocortex; i.e. the dorsal bank of the superior temporal sulcus (area TPO), the opercular area of the STG (TAa), to a lesser extent, from insular, anterior cingulate, medial and orbitofrontal cortex (Suzuki and Amaral, 1994a; Blatt et al., 2003).

In relation with auditory afferents, the rostral part of the STG (areas Ts1-3), including the TP, projects to areas 35 and 36 of the perirhinal cortex and to areas $\mathrm{TH}$ and $\mathrm{TF}$ of the posterior parahippocampal cortex. A restricted area of the caudal STG, which appears to include the caudal lateral parabelt area of the auditory cortex and area Tpt (see Figure 11 in Suzuki and Amaral, 1994a) projects specifically to area TH of the posterior parahippocampal cortex (Suzuki and Amaral, 1994a; Blatt et al., 2003). Area $\mathrm{TH}$ sends reciprocal projections to area Tpt of the caudal STG (Tranel et al., 1988). It is worth noting that, Tranel et al.'s report showed that posterior parahippocampal projections to area Tpt appear to arise exclusively in area $\mathrm{TH}$, with no projections from area TF. Area Tpt has dense connections with the caudal medial belt, where auditory and somatosensory responses have been detected electrophysiologically, suggesting that this area may be a multimodal one (CM, Smiley et al., 2007). Although the specific function of area Tpt remains still unknown, this area in monkeys shows increased regional cerebral blood flow ( $\mathrm{rCBF}$ ) in the presence of species-specific vocalizations (Gil-da-Costa et al., 2006). 
Furthermore, in humans, this area contributes substantially to the enlargement of the left planum temporale on the left hemisphere and it is considered part of Wernicke's area (Galaburda et al., 1978). Area Tpt might be, therefore, a higher order processing area related with comprehension or semantic recognition of auditory stimuli.

\section{Temporal pole}

The temporal pole has been considered part of the parahippocampal region both in humans and non-human primates (Insausti et al., 1987a; Blaizot et al., 2004; Blaizot et al., 2010). However, both architectonically, and in terms of its connections, TP is a transitional area between perirhinal cortex and the neocortical areas of the adjacent superior and inferior temporal gyri. Whereas the lateral dorsal and ventral divisions of TP (38DL, 38VL) are closely related to adjacent superior and inferior temporal gyri (Moran et al., 1987; Kondo et al., 2003; our own observations in rhesus monkeys), the medial ventral and dorsal subdivisions of TP (36p-vm, 36p-dm, in rhesus monkeys this study), have been considered as a dorsal extension of area 36 of the perirhinal cortex in different non-human primates (Insausti et al., 1987a; Suzuki and Amaral, 1994a; Blaizot et al., 2004).

Anatomical studies with wallerian degeneration techniques showed that early auditory and visual processing areas send projections to progressively more rostral portions of the STG and subsequently to TP (Jones and Powell, 1970). This stream of caudalto-rostral connections has been later confirmed with more modern tract tracing studies (Galaburda and Pandya, 1983; Markowitsch et al., 1985; Moran et al., 1987; Cipolloni and Pandya, 1989). The work of Moran et al. (1987) showed that, the dorsal part of TP receives specifically input from auditory processing areas of the STG, and therefore, may participate in auditory processing, in contrast, to other TP regions, which receive olfactory and visual input. Further support to this anatomical and functional organization of TP has been recently reported in a 2-deoxyglocose activation study in monkeys that were exposed to auditory and visual stimuli (Poremba et al., 2003). The likely involvement of the dorsal TP in high order auditory processing has been also delineated by a recent FDG-PET study in monkeys stimulated with different types of sounds including simple, complex, and naturalistic sounds (Poremba et al., 2004). According to this study, the dorsal part of TP plays a special role in processing species-specific calls in rhesus monkeys; specifically, this area showed evidence of left hemisphere specialization for processing vocalizations like that shown in humans for processing speech. In fact, we have shown that the densest afferent connections to the dorsal part of TP originate in auditory-related areas of the rostral STG (areas RTL, Ts1-Ts3) and the polymodal areas TAa and TPO (Munoz et al., 2003).

On the other hand, the dorsal lateral TP receives input from medial, orbitofrontal, and insular cortex (Mesulam, 1982; Markowitsch et al., 1985; Moran et al., 1987; Munoz et al., 2002; Kondo et al., 2003), suggesting that it may be involved in auditory and multimodal processing. The TP has reciprocal connections with EC (Kosel et al., 1982; Insausti et al., 1987a; Munoz et al., 2003), the rostral part of areas 35 and 36 of the perirhinal cortex (Munoz et al., 2003; Lavenex et al., 2004) and areas TH and TF of the posterior parahippocampal cortex (Munoz et al., 2003).
The participation of TP in memory in humans has been shown in fMRI studies, and critically, by its involvement in semantic dementia (Olson et al., 2007; Patterson et al., 2007). However, in non-human primate models of amnesia $\mathrm{TP}$ has received considerably less attention than the hippocampus and parahippocampal region, and therefore, its participation in memory remains largely unknown. Nonetheless, the anatomical position of the dorsal part of TP within the auditory cortical system and its close relation with the medial temporal cortex, suggest that it might be one important entry point of highly processed auditory information to the medial temporal cortex, and therefore, participate in auditory memory processing, in parallel to the TE-perirhinalentorhinal-hippocampus pathway in visual memory (Munoz et al., 2003).

In sum, the cortex of the rostral part of the STG, including the dorsal part of TP and, to a lesser extent, areas Ts1-3 of the auditory parabelt project directly to EC, the rostral part of areas 35 and 36 of the perirhinal cortex, and areas $\mathrm{TH}$ and TF of the posterior parahippocampal cortex. There is an additional projection from the caudal STG to area TH. The auditory projections to EC are, however, very meager in comparison with its polymodal input (Mohedano-Moriano et al., 2008). Similarly, auditory afferents to the perirhinal and posterior parahippocampal cortices are very meager compared to visual input. This is in line with the second hypothesis that the major route, by which the auditory information reaches the medial temporal cortex is via indirect connections, the dorsal TP possibly being one of the major indirect pathway (Figure 2).

\section{INDIRECT AUDITORY INPUT TO MEDIAL TEMPORAL CORTEX Dorsal bank of the superior temporal sulcus}

Neurons in the operculum and the dorsal bank of the superior temporal sulcus in the non-human primate-the superior temporal polysensory area STP - show responses to stimuli from different sensory modalities such as auditory, visual, and somatosensory (Bruce et al., 1981; Baylis et al., 1987). It is reasonable then to assume that the auditory information that reaches the medial temporal cortex via the superior temporal sulcus may not be purely auditory, but has already been integrated with information from other modalities (Figure 3).

A possible pathway, and probably the densest route of indirect projections from the auditory areas of the STG to the medial temporal cortex, would start in the rostral divisions of the lateral parabelt through a series of synaptic relays:

a) Areas Ts1-Ts2 of the gyral surface of the STG (Figure 1) send a very meager direct projection to the memory-related areas of the medial temporal cortex (Amaral et al., 1983; Insausti et al., 1987a; Suzuki and Amaral, 1994a). In contrast, they send a dense one to the opercular area TAa and to the dorsal bank of the STG (Seltzer and Pandya, 1989).

b) Area TAa of the STG (Figure 1) send a weak projection to areas of the medial temporal cortex (Amaral et al., 1983; Insausti et al., 1987a; Suzuki and Amaral, 1994a), however area TAa has dense connections with the fundus and dorsal bank of the superior temporal sulcus (areas PGa and TPO of Seltzer and Pandya, 1989; Figure 1). 


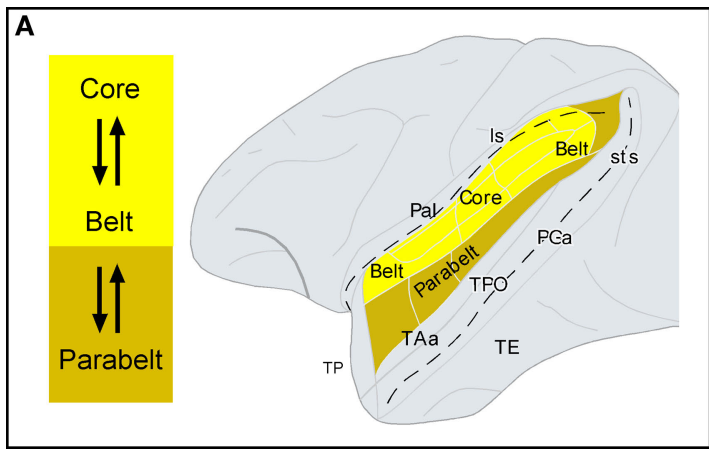

FIGURE 2 | Direct auditory pathway to the medial temporal cortex.

(A) Core and belt areas of the auditory cortex, shown in the lateral view of the primate brain, have dense and reciprocal connections. Belt areas have dense connections with parabelt areas, where the projection to the parahippocampal region originates, i.e. the direct pathway $\mathbf{( B )}$ The architectonic areas that comprise the parahippocampal region are

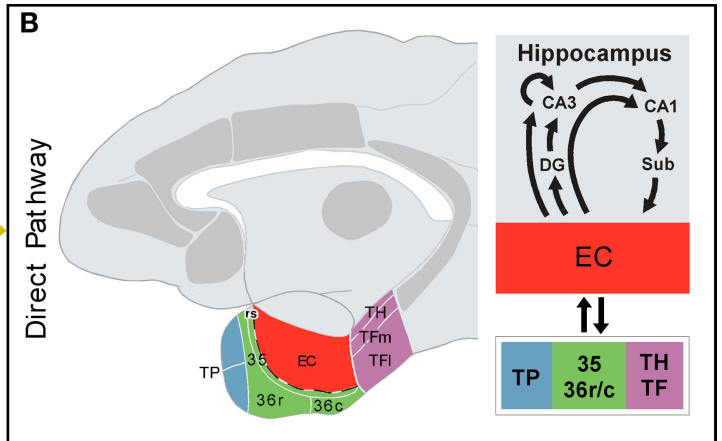

shown in a medial view of the primate brain. Additional cortical areas that receive auditory input and project to the parahippocampal region are shown in gray, but they form part of the indirect pathway (see Figure $\mathbf{3}$ for further details). Connections between the parahippocampal region and the hippocampal formation are summarized on the right-hand side. See list of abbreviations.

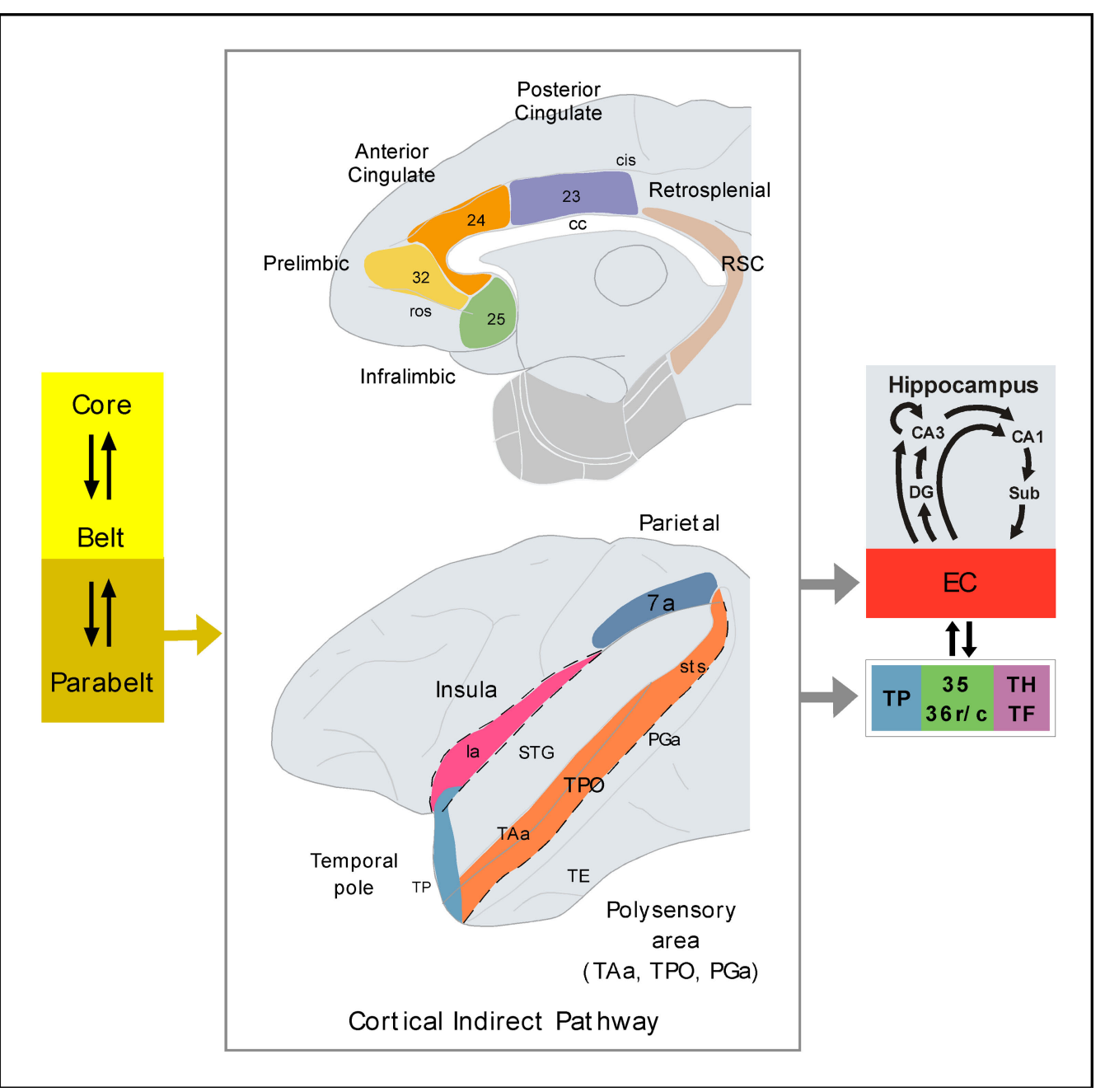

FIGURE 3 | Possible indirect pathways of auditory information to the medial temporal cortex. The schematic diagram of the primate brain illustrates the cortical areas reported to receive connections from parabelt areas of the auditory cortex and, critically, to send projections to the medial temporal cortex. The cortical areas shown in the figure represent synaptic relays of auditory information before it reaches the medial temporal memory system. The parahippocampal region is shown in light gray. See list of abbreviations. 
c) Areas PGa and TPO (Figure 1) send projections to the entorhinal, perirhinal and posterior parahippocampal cortices, with the latter area originating the densest projection of all (Amaral et al., 1983; Insausti et al., 1987a; Suzuki and Amaral, 1994a).

In summary, one of the routes for auditory afferents to reach the hippocampal formation, perirhinal, and posterior parahippocampal cortices might be through polymodal areas of the dorsal bank of the superior temporal sulcus (Figure 3).

\section{Insula}

One of the sources of auditory information to the insula (Figure 3) originates within the superior temporal plane and especially in the more medial portions of the auditory belt area (Mufson and Mesulam, 1982). These projections form part of the complex pattern of afferent projections to the insular cortex, suggesting that the insula, among other functions, is involved in auditory processing.

Auditory-insular connections have received little attention, but a recent study reported that auditory-related areas located in the medial and lateral subdivisions of the caudal belt receive somatosensory information from retroinsular and granular insular cortex (Smiley et al., 2007). These areas also receive visual information from area prostriata localized in the anterior portion of the calcarine sulcus, visual cortex area V2, the polysensory area TPO of the dorsal bank of the superior temporal sulcus, and area Tpt (Falchier et al., 2010). Therefore, the medial and lateral caudal divisions of the auditory belt might themselves process polysensory information in higher degree than had previously been thought.

The agranular and disgranular divisions of the insula send dense projections to the rostromedial division of EC (Insausti et al., 1987a; Insausti and Amaral, 2008) to area 35, and to lesser extent to area 36 of the perirhinal cortex, and to the posterior parahippocampal areas TH and TF (Suzuki and Amaral, 1994a). This might be a second important source of indirect auditory input to the medial temporal cortex.

\section{Anterior cingulate, prelimbic, and infralimbic cortex}

Area 32 (Barbas, 1988), and areas 25 and 24 (Figure 3, Vogt and Pandya, 1987; Petrides and Pandya, 1988; Barbas et al., 1999; Munoz et al., 2009) receive strong projections from auditory association areas of the rostral STG, including parabelt and TP, primarily via the uncinate fasciculus. In contrast, the medial frontal cortex in marmosets receives projections from earlier (core) auditory processing areas (Roberts et al., 2007; Reser et al., 2009). These studies revealed another interesting difference between macaque and marmoset monkeys. Unlike rhesus monkeys, the medial frontal cortex of the marmoset monkey receive visual information via ventral temporal pole and inferior temporal gyrus. The temporal-medial frontal connections in marmosets appear, therefore, to arise earlier in the auditory sensory stream and might be less sensory-specific compared with macaque monkeys.

The STG-medial frontal projections in rhesus monkeys are organized topographically, in such a manner that the density of the projection decreases progressively from rostral to caudal in the STG. The lateral portion of TP and area Ts1 are the origin of the densest projection to areas 25,32, and to a lesser extent to area
24, whereas the density of the projection decreases progressively from area Ts2 to Ts3 (Vogt and Pandya, 1987; Petrides and Pandya, 1988; Barbas et al., 1999). These auditory-processing projections are reciprocal, therefore axons from the anterior lateral, medial prefrontal, and orbitofrontal areas terminate in the anterior half of the STG (Barbas et al., 2005).

Areas 32, 24, and 25 have been associated with the production of calls in squirrel monkeys (Jürgens and Pratt, 1979; Kirzinger and Jurgens, 1982). Although the extensive work of Jürgens has elucidated the major pathways involved in the motor control of monkey vocalizations in the squirrel monkey, little is known in rhesus monkeys. In the late sixties, Robinson found that electrical stimulation of different territories of the medial frontal cortex elicited monkey calls in rhesus monkeys (primarily area 32, but it may be also area 24, Robinson, 1967; see review in Vogt and Barbas, 1987).

Ventral medial frontal areas 24, 32, and 25 have, on the other hand, lead the frontal projections with medial temporal cortex. In fact, among all the architectonic areas that form the frontal cortex, areas 25 and 32 have the densest connections with CA1/ Subiculum and, and therefore, have a very direct access to the medial temporal memory system (Barbas and Blatt, 1995; Blatt and Rosene, 1998; Barbas et al., 1999; Insausti and Munoz, 2001). A similar pattern of frontal-hippocampal formation connections has been reported in marmosets (Roberts et al., 2007). Areas 24, 32 , and 25 also send connections to TP, EC, and the posterior parahippocampal cortices and, to a lesser extent, with to 36 and 35 of the perirhinal cortex (Insausti et al., 1987a; Arikuni et al., 1994; Suzuki and Amaral, 1994a).

Although the role of these regions of the medial frontal cortex in working or long-term memory in audition is still puzzling, removals that include area 25 impair visual long-term recognition memory in monkeys (Bachevalier and Mishkin, 1986). In fact, Bachevalier and Mishkin (1986) suggested that, together with the medial thalamus and the medial temporal cortex, area 25 forms part of the limbic system important for episodic memory. Whether the role in recognition of area 25 is extensive to other sensory modalities, such as the auditory or somatosensory, calls for further research. Interestingly, the auditory input to areas 25,32 , and the pregenual portion of area 24 of the frontal cortex is disrupted by medial temporal removals (Munoz et al., 2009), the very same lesions that impair auditory (short-term) recognition memory (Fritz et al., 2005).

In sum, the complex anatomical and physiological organization of the medial frontal cortex suggests that areas 24,25 , and 32 are involved in some motor aspects of monkey call production, amongst other functions. In addition, they interact with auditory and medial temporal cortices and therefore, they may modulate auditory memory function. Emotional modulation of auditory memory might be mediated possibly by way of interactions via connections with the amygdala (Aggleton et al., 1980; Barbas, 1995) or autonomic responses through the hypothalamus (Ongur et al., 1998; Chiba et al., 2001).

\section{Posterior cingulate and retrosplenial cortex}

Superior temporal gyrus projections to area 23 of the caudal cingulate cortex and to areas 29 and 30 have been described by in retrograde tracer experiments, but they have been reported as very 
modest and arising primarily from the dorsal bank of the superior temporal sulcus, rather than from auditory processing areas (Vogt and Pandya, 1987; Kobayashi and Amaral, 2003).

However, there might be a modest contribution of auditory projections to caudal cingulate (area 23) and retrosplenial cortex (area 29) as well as caudal presubiculum (Yukie, 1995), both of which project to EC (Insausti et al., 1987a).

Area 29 of the retrosplenial cortex and area 23 of the posterior cingulate cortex are important sources of cortical afferents to the caudal entorhinal cortex, the posterior parahippocampal areas $\mathrm{TH}$ and $\mathrm{TF}$, and to a lesser extent, to perirhinal cortex areas 35 and 36.

\section{Parietal cortex}

The intraparietal sulcus is involved in spatial auditory processing (Cohen and Andersen, 2000; Cohen et al., 2004). Functional imaging and event-related potential studies in humans also indicate that the parietal cortex, particularly in the right hemisphere, is active during tasks requiring active localization of sounds (Maeder et al., 2001).

Some studies have failed to find direct connections between auditory areas of the STG and the intraparietal sulcus (Cavada and Goldman-Rakic, 1989; Neal et al., 1990), and it has therefore auditory information likely reaches the intraparietal sulcus primarily via area Tpt (Smiley et al., 2007) and the dorsal bank of the superior temporal sulcus (Neal et al., 1990).

Tract tracing studies indicate that the medial part of area Tpt in the caudal STG sends projections to the ventral intraparietal area, an area that has been involved in neuroanatomical networks functionally related to visual, vestibular, somatomotor, and auditory processing (Lewis and Van Essen, 2000).

In sum, this pathway arises in the caudal parabelt areas and projects via inferior pariental cortex (area 7a) to areas TH and TF of the posterior parahippocampal cortex (Suzuki and Amaral, 1994a) and to caudal entorhinal cortex (Insausti et al., 1987a).

\section{Amygdala and thalamus}

The amygdaloid complex, a group of nuclei with dense cortical and hypothalamic connections, is important in emotion, motivation, memory, and social behavior.

Connections between auditory-related areas of the rostral half of the STG and the amygdala in monkeys have been reported previously (Nauta, 1961; Aggleton et al., 1980; Van Hoesen, 1981; Amaral and Price, 1984; Stefanacci and Amaral, 2002). Within the amygdaloid complex, the lateral nucleus receives the densest projection from auditory-related areas. There is then an intrinsic projection from the lateral nucleus to the lateral basal nucleus (Pitkanen and Amaral, 1991, 1998), and the lateral basal nucleus sends reciprocal projections to auditory processing cortical areas. There is some indication that this amygdalofugal outflow of projections to cortical areas, including that to auditory-related areas, might be more widespread and more complex than the afferent projections (Amaral and Price, 1984).

The lateral nucleus of the amygdala provides the densest input to EC, with additional projections also originating in the basal and accessory basal nucleus (Insausti et al., 1987b; Saunders et al., 1988; Pitkanen et al., 2002; Stefanacci and Amaral, 2002). It is interesting to note that the projections from some cortical and subcortical areas converges with auditory input in to the lateral EC (Amaral et al., 1983; Insausti et al., 1987b; Mohedano-Moriano et al., 2007; Mohedano-Moriano et al., 2008).

The amygdala, therefore, may influence EC, and moreover has further access to the hippocampus. Many of the amygdalar nuclei, primarily basal, lateral basal, medial basal, cortical nucleus and cortical-amygdaloid area send direct projections to the molecular layer of the amygdalo-hippocampal area and stratum lacunosum moleculare of the uncal portions of CA3 and less densely to CA1, and the CA1/Subiculum area, also called prosubiculum. Additional projections terminate in the presubiculum, parasubiculum, and layers I-III of the rostral one-half of EC (Rosene and Van Hoesen, 1977; Aggleton, 1986; Saunders et al., 1988).

In non-human primates, there is a direct thalamo-amygdaloid pathway that seems to be relatively minor. Among the multiple thalamic nuclei, only the peripeduncular nucleus was found to project substantially to the lateral amygdaloid nucleus (Jones et al., 1976; Aggleton et al., 1980; Amaral and Insausti, 1992). This connection is prominent in rats and has been considered to be a rapid route for acoustic signals of emotional significance (LeDoux et al., 1990). In non-human primates, the direct thalamo-amygdaloid projections seem to be less dense compared with the connections between the amygdala and cortical auditory processing areas.

Classical degeneration and more modern neuronal tracer techniques have been employed to discover and describe the thalamic connections to auditory areas (De Vito and Simmons, 1976; Kosmal et al., 1997; Hackett et al., 1998; Gutierrez et al., 2000; Hackett et al., 2007). The thalamic nucleus that leads the projection to the core, belt, and parabelt areas of the auditory cortex is the medial geniculate nucleus (MGd or MGv), but this cortical area also receives inputs from other thalamic nuclei such as the suprageniculate nucleus, limitans, medial dorsal, and rostral and medial nuclei of the pulvinar (Pandya et al., 1994; Hackett et al., 1998).

In the thalamus, the medial nucleus of the pulvinar, an area of multimodal convergence (Cappe et al., 2009), has been involved in sensory integration and attention (Ivanov et al., 2010), although its function remains not well understood. On one hand, the medial pulvinar is connected with the rostral part of STG (Trojanowski and Jacobson, 1975). On the other hand, the rostral and lateral divisions of EC, the same ones that receive direct auditory input and indirect via amygdala, receive also dense projections from the medial nucleus of the pulvinar (Trojanowski and Jacobson, 1977; Insausti et al., 1987b). It seems, therefore, that this thalamic nucleus may form part of the indirect subcortical pathway for audition to reach the medial temporal memory system.

\section{CONCLUDING REMARKS}

The primary aim of this review has been to draw attention to the complexity of additional indirect connections by which auditory information can get to memory processing areas of the medial temporal lobes. Specifically, the anatomical studies reviewed here indicate that, unlike the strong, direct and reciprocal connections of visual association areas between the inferior temporal cortex and areas 35 and 36 of the perirhinal and areas TH and TF of the posterior parahippocampal cortex, direct connections from auditory processing areas of the STG with medial temporal cortex appear 


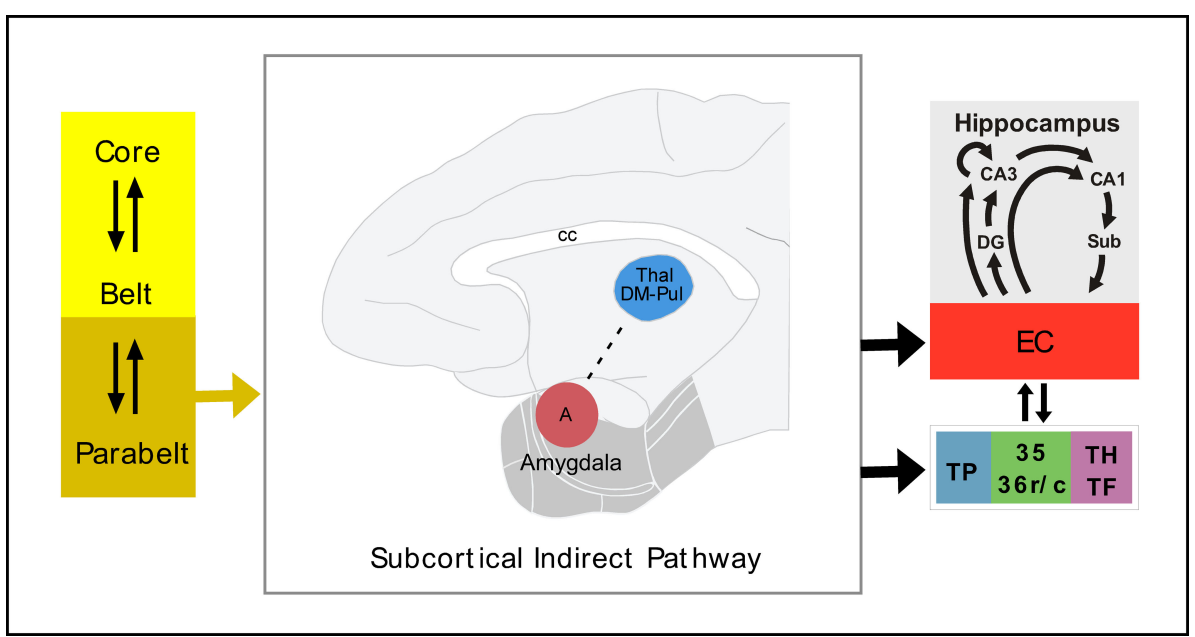

FIGURE 4 | Possible subcortical indirect pathway for auditory input to the medial temporal memory system. See list of abbreviations.

to be considerably more modest. Thus, whereas the visual "ventral stream" of processing in the Mishkin and Ungerleider (1982) framework is relatively direct, this principle does not appear to extend to the auditory domain. This may explain, at least in part, monkeys' poor ability for auditory memory (Fritz et al., 2005).

The entry of auditory information to the medial temporal cortex might be, therefore, more indirect in audition than in vision. In addition to the cortical direct and indirect pathways, auditory information may enter the medial temporal cortex via subcortical structures, like the lateral and basal nuclei of the amygdala and the thalamus, with possibly an especial role for the medial pulvinar. The direct connections of the amygdala with the hippocampus points to a possible role of emotion in auditory longterm memory.

It cannot be ruled out the contribution of other subcortical nuclei in the diencephalon or brainstem, although little or no neuroanatomical evidence exists. It is foreseeable that the

\section{REFERENCES}

Aggleton, J. P. (1986). A description of the amygdalo-hippocampal interconnections in the macaque monkey. Exp. Brain Res. 64, 515-526.

Aggleton, J. P., and Brown, M. W. (1999). Thanks for the memories, Extending the hippocampal-diencephalic memonic system. Behav. Brain Sci. 22, 471-489.

Aggleton, J. P., Burton, M. J., and Passingham, R. E. (1980). Cortical and subcortical afferents to the amygdala of the rhesus monkey (Macaca mulatta). Brain Res. 190, 347-368.

Amaral, D. G., and Insausti, R. (1992). Retrograde transport of $\mathrm{D}-[3 \mathrm{H}]$ aspartate injected into the monkey amygdaloid complex. Exp. Brain Res. 88, 375-388.

Amaral, D. G., Insausti ,R., and Cowan, W. M. (1983). Evidence for a direct projection from the superior temporal gyrus to the entorhinal cortex in the monkey. Brain Res. 275, 263-277.

Amaral, D. G., Insausti, R., and Cowan, W. M. (1987). The entorhinal cortex of the monkey: I. Cytoarchitectonic organization. J. Comp. Neurol. 264, 326-355.

Amaral, D. G., and Price, J. L. (1984). Amygdalo-cortical projections in the monkey (Macaca fascicularis). J. Comp. Neurol. 230, 465-496.

Arikuni, T., Sako, H., and Murata, A. (1994). Ipsilateral connections of the anterior cingulate cortex with the frontal and medial temporal cortices in the macaque monkey. Neurosci. Res. 21, 19-39.

Bachevalier, J., and Mishkin, M. (1986). Visual recognition impairment follows ventromedial but not dorsolateral

auditory memory involves much more intricate and complex neural networks and that all this information may be translated to clinical practice.

The projections of neurons in auditory processing areas of the STG seem to reach memory-related areas of the medial temporal cortex and diencephalon via indirect connections with polysensory areas (Figure 3), such as the TP, the dorsal bank of the superior temporal sulcus, the insula, medial frontal cortex (areas 24,32, and 25), and to a lesser extent posterior cingulate and retrosplenial cortex, and via amygdale and medial pulvinar (Figure 4). This is in line with the second of the two hypotheses we have considered, although there remain a number of unresolved issues (Table 1). Specifically, unlike in vision, the majority of auditory connections, before they reach the medial temporal cortex, make additional synaptic connections in intermediate, polymodal areas where they integrate with information from other sensory modalities, and only then do they enter in the medial temporal lobe memory system.

prefrontal lesions in monkeys. Behav. Brain Res. 20, 249-261.

Barbas, H. (1988). Anatomic organization of basoventral and mediodorsal visual recipient prefrontal regions in the rhesus monkey. J. Comp. Neurol. 276, 313-342.

Barbas, H. (1995). Anatomic basis of cognitive-emotional interactions in the primate prefrontal cortex. Neurosci. Biobehav. Rev. 19, 499-510.

Barbas, H., and Blatt, G. J. (1995) Topographically specific hippocampal projections target functionally distinct prefrontal areas in the rhesus monkey. Hippocampus 5, 511-533.

Barbas, H., Ghashghaei, H., Dombrowski, S. M., and Rempel-Clower, N. L. (1999). Medial prefrontal cortices are unified by common connections with superior temporal cortices and distinguished by input from memoryrelated areas in the rhesus monkey. $J$. Comp. Neurol. 410, 343-367.

Barbas, H., Medalla, M., Alade, O., Suski, J., Zikopoulos, B., and Lera, P. (2005). Relationship of prefrontal connections to inhibitory systems in superior temporal areas in the rhesus monkey. Cereb. Cortex 15, 1356-1370.

Baylis, G. C., Rolls, E. T., and Leonard, C. M. (1987). Functional subdivisions of the temporal lobe neocortex. $J$. Neurosci. 7, 330-342.

Blaizot, X., Mansilla, F., Insausti, A. M., Constans, J. M., Salinas-Alaman, A., Pro-Sistiaga, P., Mohedano-Moriano, A., and Insausti, R., (2010). The human parahippocampal region: I. Temporal pole cytoarchitectonic and MRI correlation. Cereb. Cortex. 20, 2198-2212. 
Blaizot, X., Martinez-Marcos, A., ArroyoJimenez, M. M., Marcos, P., ArtachoPerula, E., Munoz, M., Chavoix, C., and Insausti, R. (2004). The parahippocampal gyrus in the baboon, anatomical, cytoarchitectonic and magnetic resonance imaging (MRI) studies. Cereb. Cortex 14, 231-246.

Blatt, G. J., Pandya, D. N., and Rosene, D. L. (2003). Parcellation of cortical afferents to three distinct sectors in the parahippocampal gyrus of the rhesus monkey, an anatomical and neurophysiological study. J. Comp. Neurol. 466, 161-179.

Blatt, G. J., and Rosene, D. L. (1998). Organization of direct hippocampal efferent projections to the cerebral cortex of the rhesus monkey, projections from CA1, prosubiculum, and subiculum to the temporal lobe. J. Comp. Neurol. 392, 92-114.

Brodmann, K. (1909). Vergleichende Lokalisationslehere der Grosshimrinde in ihren Principien dargestellt auf des Grund des Zellenbayes. Barth, Leipzig.

Brown, M. W., and Aggleton, J. P. (2001). Recognition memory, what are the roles of the perirhinal cortex and hippocampus? Nat. Rev. Neurosci. 2, 51-61.

Bruce, C., Desimone, R., and Gross, C. G. (1981). Visual properties of neurons in a polysensory area in superior temporal sulcus of the macaque. $J$. Neurophysiol. 46, 369-384.

Burwell, R. D., Witter, M. P., and Amaral, D. G. (1995). Perirhinal and postrhinal cortices of the rat, a review of the neuroanatomical literature and comparison with findings from the monkey brain. Hippocampus 5, 390-408.

Cappe, C., Morel, A., Barone, P., and Rouiller, E. M. (2009). The thalamocortical projection systems in primate, an anatomical support for multisensory and sensorimotor interplay. Cereb. Cortex 19, 2025-2037.

Cavada, C., and Goldman-Rakic, P. S. (1989). Posterior parietal cortex in rhesus monkey, I. Parcellation of areas based on distinctive limbic and sensory corticocortical connections. J. Comp. Neurol. 287, 393-421.

Chiba, T., Kayahara, T., and Nakano, K. (2001). Efferent projections of infralimbic and prelimbic areas of the medial prefrontal cortex in the Japanese monkey, Macaca fuscata. Brain Res. 888, 83-101.

Cipolloni, P. B., and Pandya, D. N. (1989). Connectional analysis of the ipsilateral and contralateral afferent neurons of the superior temporal region in the rhesus monkey. J. Comp. Neurol. 281, 567-585.
Cohen, Y. E., and Andersen, R. A. (2000). Reaches to sounds encoded in an eyecentered reference frame. Neuron 27 647-652.

Cohen, Y. E., Cohen, I. S., and Gifford, G. W. (2004). Modulation of LIP activity by predictive auditory and visual cues. Cereb. Cortex 14, 1287-1301.

De Vito, J. L., and Simmons, D. M. (1976). Some connections of the posterior thalamus in monkey. Exp. Neurol. 51, 347-362.

Engelien, A., Stern, E., Isenberg, N., Engelien, W., Frith, C., and Silbersweig, D. (2000). The parahippocampal region and auditory-mnemonic processing. Ann. N. Y. Acad. Sci. 911, 477-485.

Falchier, A., Schroeder, C. E., Hackett, T. A., Lakatos, P., Nascimento-Silva, S., Ulbert, I., Karmos, G., and Smiley, J. F. (2010). Projection from visual areas V2 and prostriata to caudal auditory cortex in the monkey. Cereb. Cortex 20, 1529-1538.

Fritz, J., Mishkin, M., and Saunders, R. C. (2005). In search of an auditory engram. Proc. Natl. Acad. Sci. U. S. A. 102, 9359-9364.

Galaburda, A. M., and Pandya, D. N. (1983). The intrinsic architectonic and connectional organization of the superior temporal region of the rhesus monkey. J. Comp. Neurol. 221, 169-184.

Galaburda, A. M., Sanides, F., and Geschwind, N. (1978). Human brain. Cytoarchitectonic left-right asymmetries in the temporal speech region. Arch. Neurol. 35, 812-817.

Gil-da-Costa, R., Braun, A., Lopes, M., Hauser, M. D., Carson, R. E., Herscovitch, P., and Martin, A. (2004) Toward an evolutionary perspective on conceptual representation, species-specific calls activate visual and affective processing systems in the macaque. Proc. Natl. Acad. Sci. U.S.A. 101, 17516-17521.

Gil-da-Costa, R., Martin, A., Lopes, M.A., Munoz, M., Fritz, J. B., and Braun, A. R. (2006). Species-specific calls activate homologs of Broca's and Wernicke's areas in the macaque. Nat. Neurosci. 9, 1064-1070.

Gutierrez, C., Cola, M. G., Seltzer, B., and Cusick, C. (2000). Neurochemical and connectional organization of the dorsal pulvinar complex in monkeys. $J$. Comp. Neurol. 419, 61-86.

Hackett, T.A. (2010). Information flow in the auditory cortical network. Hear. Res. [Epub ahead of print]

Hackett, T.A., de la Mothe, L. A., Ulbert, I., Karmos, G., Smiley, J., and Schroeder, C.E. (2007). Multisensory convergence in auditory cortex, II. Thalamocortical connections of the caudal superior temporal plane. J. Comp. Neurol. 502, 924-952.

Hackett, T. A., Stepniewska, I., and Kaas, J. H. (1998). Subdivisions of auditory cortex and ipsilateral cortical connections of the parabelt auditory cortex in macaque monkeys. J. Comp. Neurol. 394, 475-495.

Insausti, R. (1993). Comparative anatomy of the entorhinal cortex and hippocampus in mammals. Hippocampus 3 Spec No, 19-26.

Insausti, R., and Amaral, D. G. (2008) Entorhinal cortex of the monkey, IV. Topographical and laminar organization of cortical afferents. J. Comp. Neurol. 509, 608-641.

Insausti, R., Amaral, D. G., and Cowan, W. M. (1987a). The entorhinal cortex of the monkey, II. Cortical afferents. J. Comp. Neurol. 264, 356-395.

Insausti, R., Amaral, D. G., and Cowan, W. M. (1987b). The entorhinal cortex of the monkey, III. Subcortical afferents. J. Comp. Neurol. 264, 396-408.

Insausti, R., and Munoz, M. (2001). Cortical projections of the nonentorhinal hippocampal formation in the cynomolgus monkey (Macaca fascicularis). Eur. J. Neurosci. 14, 435-451.

Ivanov, I., Bansal, R., Hao, X., Zhu, H., Kellendonk, C., Miller, L., SanchezPena, J., Miller, A. M., Chakravarty, M M., Klahr, K., Durkin, K., Greenhill, L. L., and Peterson, B. S. (2010) Morphological abnormalities of the thalamus in youths with attention deficit hyperactivity disorder. Am. J. Psychiatry 167, 397-408.

Jones, E. G., Burton, H., Saper, C. B., and Swanson, L. W. (1976). Midbrain, diencephalic and cortical relationships of the basal nucleus of Meynert and associated structures in primates. J. Comp. Neurol. 167, 385-419.

Jones, E. G., and Powell, T. P. (1970). An anatomical study of converging sensory pathways within the cerebral cortex of the monkey. Brain 93 793-820.

Jürgens, U., and Pratt, R. (1979). The cingular vocalization pathway in the squirrel monkey. Exp. Brain Res. 34, 499-510.

Kaas, J. H., and Hackett, T. A. (2000) Subdivisions of auditory cortex and processing streams in primates. Proc. Natl. Acad. Sci. U.S.A. 97, 11793-11799.

Kikuchi, Y., Horwitz, B., and Mishkin, M. (2006). Neural representation of auditory stimulus-quality in monkey's rostral supratemporal plane. Soc. Neurosci. Abstract 344.6.Atlanta, GA, USA.

Kirzinger, A., and Jurgens, U. (1982) Cortical lesion effects and vocalization in the squirrel monkey. Brain Res. 233 , 299-315.

Kobayashi, Y., and Amaral, D. G. (2003) Macaque monkey retrosplenial cortex, II. Cortical afferents. J. Comp. Neurol. 466, 48-79.

Kondo, H., Saleem, K. S., and Price, J. L. (2003). Differential connections of the temporal pole with the orbital and medial prefrontal networks in macaque monkeys. J. Comp. Neurol. 465, 499-523.

Konorski, J. (1959). A new method of physiological investigation of recent memory in animals. Bull. Acad. Pol. Sci. CL II, Ser. Sci. Biol. 7, 115-117.

Kosel, K.C., Van Hoesen, G.W., and Rosene, D. L. (1982). Non-hippocampal cortical projections from the entorhinal cortex in the rat and rhesus monkey. Brain Res. 244, 201-213.

Kosmal, A., Malinowska, M., and Kowalska, D.M. (1997). Thalamic and amygdaloid connections of the auditory association cortex of the superior temporal gyrus in rhesus monkey (Macaca mulatta). Acta Neurobiol. Exp. (Wars.) 57, 165-188.

Lavenex, P., Suzuki, W. A., and Amaral, D. G. (2002). Perirhinal and parahippocampal cortices of the macaque monkey, projections to the neocortex. J. Comp. Neurol. 447, 394-420.

Lavenex, P., Suzuki, W. A., and Amaral, D. G. (2004). Perirhinal and parahippocampal cortices of the macaque monkey, Intrinsic projections and interconnections. J. Comp. Neurol. 472, 371-394.

LeDoux, J.E., Farb, C., and Ruggiero, D. A. (1990). Topographic organization of neurons in the acoustic thalamus that project to the amygdala. J. Neurosci. 10, 1043-1054

Lewis, J. W., and Van Essen, D. C. (2000). Corticocortical connections of visual, sensorimotor, and multimodal processing areas in the parietal lobe of the macaque monkey. J. Comp. Neurol. 428, 112-137.

Maeder, P. P., Meuli, R. A., Adriani, M., Bellmann, A., Fornari, E., Thiran, J. P., Pittet,A., and Clarke, S. (2001).Distinct pathways involved in sound recognition and localization, a human fMRI study. Neuroimage 14, 802-816.

Markowitsch, H. J., Emmans, D., Irle, E., Streicher, M., and Preilowski, B. (1985). Cortical and subcortical afferent connections of the primate's temporal pole, a study of rhesus monkeys, squirrel monkeys, and marmosets. $J$. Comp. Neurol. 242, 425-458.

Mesulam, M. M. (1982). Slowly progressive aphasia without generalized dementia. Ann. Neurol. 11, 592-598.

Meunier, M., Bachevalier, J., Mishkin, M. and Murray, E. A. (1993). Effects on 
visual recognition of combined and separate ablations of the entorhinal and perirhinal cortex in rhesus monkeys. J. Neurosci. 13, 5418-5432.

Mishkin, M. (1978). Memory in monkeys severely impaired by combined but not by separate removal of amygdala and hippocampus. Nature 273, 297-298.

Mishkin, M., and Ungerleider, L. G. (1982). Contribution of striate inputs to the visuospatial functions of parieto-preoccipital cortex in monkeys. Behav. Brain Res. 6, 57-77.

Mohedano-Moriano, A., MartinezMarcos, A., Pro-Sistiaga, P., Blaizot, X., Arroyo-Jimenez, M. M., Marcos, P., Artacho-Perula, E., and Insausti, R. (2008). Convergence of unimodal and polymodal sensory input to the entorhinal cortex in the fascicularis monkey. Neuroscience 151, 255-271.

Mohedano-Moriano, A., Pro-Sistiaga, P., Arroyo-Jimenez, M. M., ArtachoPerula, E., Insausti, A. M., Marcos, P., Cebada-Sanchez, S., Martinez-Ruiz, J., Munoz, M., Blaizot, X., MartinezMarcos, A., Amaral, D. G., and Insausti, R. (2007). Topographical and laminar distribution of cortical input to the monkey entorhinal cortex. J. Anat. 211, 250-260.

Moran, M.A., Mufson, E. J., and Mesulam, M. M. (1987). Neural inputs into the temporopolar cortex of the rhesus monkey. J. Comp. Neurol. 256, 88-103.

Mufson, E. J., and Mesulam, M.M. (1982). Insula of the old world monkey. II, Afferent cortical input and comments on the claustrum. J. Comp. Neurol. 212, 23-37.

Munoz, M., and Insausti, R. (2005). Cortical efferents of the entorhinal cortex and the adjacent parahippocampal region in the monkey (Macaca fascicularis). Eur. J. Neurosci. 22, 1368-1388.

Munoz, M., Mishkin, M., and Saunders, R. C. (2002). Cortical connections of the lateral pole. Soc. Neurosci. Abstract 183.14.Orlando, FL, USA

Munoz, M., Mishkin, M., and Saunders, R. C. (2003). Lateral temporal pole, input from the superior temporal gyrus and output to the medial temporal cortex in the rhesus monkey. Soc. Neurosci. Abstract 939.1. New Orleans, LA, USA.

Munoz, M., Mishkin, M., and Saunders, R. C. (2009). Resection of the medial temporal lobe disconnects the rostral superior temporal gyrus from some of its projection targets in the frontal lobe and thalamus. Cereb. Cortex 19, 2114-2130.

Munoz,M., and Morris, R. (2009). Episodic Memory, Assessment in Animals.
Encyclopedia of Neuroscience. Oxford: Academic Press, pp. 1173-1182.

Nauta, W. J. (1961). Fibre degeneration following lesions of the amygdaloid complex in the monkey. J. Anat. 95, 515-531.

Neal, J. W., Pearson, R. C., and Powell, T. P. (1990). The connections of area PG, $7 \mathrm{a}$, with cortex in the parietal, occipital and temporal lobes of the monkey. Brain Res. 532, 249-264.

Ng, C. W., Plakke, B., and Poremba, A. (2009). Primate auditory recognition memory performance varies with sound type. Hear. Res. 256, 64-74.

Olson, I. R., Plotzker, A., and Ezzyat, Y. (2007). The Enigmatic temporal pole, a review of findings on social and emotional processing. Brain 130, 1718-1731.

Ongur, D., An, X., and Price, J. L. (1998). Prefrontal cortical projections to the hypothalamus in macaque monkeys. J. Comp. Neurol. 401, 480-505.

Pandya, D. N., Rosene, D. L., and Doolittle, A. M. (1994). Corticothalamic connections of auditory-related areas of the temporal lobe in the rhesus monkey. J. Comp. Neurol. 345, 447-471.

Pandya, D. N., and Sanides, F. (1973). Architectonic parcellation of the temporal operculum in rhesus monkey and its projection pattern. Z. Anat. Entwicklungsgesch. 139, 127-161.

Patterson, K., Nestor, P. J., and Rogers, T. T. (2007). Where do you know what you know? The representation of semantic knowledge in the human brain. Nat. Rev. Neurosci. 8, 976-987.

Petkov, C. I., Kayser, C., Steudel, T., Whittingstall, K., Augath, M., and Logothetis, N. K. (2008). A voice region in the monkey brain. Nat. Neurosci. 11,367-374.

Petrides, M., and Pandya, D. N. (1988). Association fiber pathways to the frontal cortex from the superior temporal region in the rhesus monkey. J. Comp. Neurol. 273, 52-66.

Pitkanen, A., and Amaral, D. G. (1991). Demonstration of projections from the lateral nucleus to the basal nucleus of the amygdala, a PHA-L study in the monkey. Exp. Brain Res. 83, 465-470.

Pitkanen, A., and Amaral, D. G. (1998). Organization of the intrinsic connections of the monkey amygdaloid complex, projections originating in the lateral nucleus. J. Comp. Neurol. 398, 431-458.

Pitkanen, A., Kelly, J. L., and Amaral, D. G. (2002). Projections from the lateral, basal, and accessory basal nuclei of the amygdala to the entorhinal cortex in the macaque monkey. Hippocampus 12, 186-205.

Poremba, A., Malloy, M., Saunders, R. C., Carson, R. E., Herscovitch, P., and
Mishkin, M. (2004). Species-specific calls evoke asymmetric activity in the monkey's temporal poles. Nature 427 , 448-451.

Poremba,A., Saunders, R. C., Crane, A.M. Cook, M., Sokoloff, L., and Mishkin, M. (2003). Functional mapping of the primate auditory system. Science 299 , 568-572.

Prisko, L. (1963). PhD Thesis. Montreal: McGill University.

Reser, D. H., Burman, K. J., Richardson, K. E., Spitzer, M. W., and Rosa, M. G. (2009). Connections of the marmoset rostrotemporal auditory area, express pathways for analysis of affective content in hearing. Eur. J. Neurosci. 30, 578-592.

Roberts, A. C., Tomic, D. L., Parkinson, C. H., Roeling, T. A., Cutter, D. J., Robbins, T.W., and Everitt, B. J. (2007) Forebrain connectivity of the prefrontal cortex in the marmoset monkey (Callithrix jacchus), an anterograde and retrograde tract-tracing study. $J$. Comp. Neurol. 502, 86-112.

Robinson, B. (1967). Vocalization evoked from forebrain in Macaca mulatta. Physiol. Behav. 2, 345-354.

Romanski, L. M., Bates, J.F., and GoldmanRakic, P. S. (1999a). Auditory belt and parabelt projections to the prefrontal cortex in the rhesus monkey. J. Comp. Neurol. 403, 141-157.

Romanski, L. M., Tian, B., Fritz, J., Mishkin, M., Goldman-Rakic, P. S. and Rauschecker, J. P. (1999b). Dual streams of auditory afferents target multiple domains in the primate prefrontal cortex. Nat. Neurosci. 2 , 1131-1136.

Rosene, D. L., and Van Hoesen, G. W. (1977). Hippocampal efferents reach widespread areas of cerebral cortex and amygdala in the rhesus monkey. Science 198, 315-317.

Saunders, R. C., Rosene, D. L., and Van Hoesen, G. W. (1988). Comparison of the efferents of the amygdala and the hippocampal formation in the rhesus monkey, II. Reciprocal and non-reciprocal connections. J. Comp. Neurol. 271, 185-207.

Schneider, R. J., Friedman, D. P., and Mishkin, M. (1993). A modalityspecific somatosensory area within the insula of the rhesus monkey. Brain Res. 621, 116-120.

Scoville, W. B., and Milner, B. (1957). Loss of recent memory after bilateral hippocampal lesions.J. Neurol. Neurosurg. Psychiatry 20, 11-21.

Seltzer, B., and Pandya, D. N. (1978). Afferent cortical connections and architectonics of the superior temporal sulcus and surrounding cortex in the rhesus monkey. Brain Res. 149, $1-24$.
Seltzer, B., and Pandya, D. N. (1989). Intrinsic connections and architectonics of the superior temporal sulcus in the rhesus monkey. J. Comp. Neurol. 290, 451-471.

Smiley, J. F., Hackett, T. A., Ulbert, I., Karmas, G., Lakatos, P., Javitt, D. C., and Schroeder, C. E. (2007). Multisensory convergence in auditory cortex, I. Cortical connections of the caudal superior temporal plane in macaque monkeys. J. Comp. Neurol. 502, 894-923.

Squire, L. R., and Zola-Morgan, S. (1991). The medial temporal lobe memory system. Science 253 , 1380-1386.

Stefanacci, L., and Amaral, D. G. (2002). Some observations on cortical inputs to the macaque monkey amygdala, an anterograde tracing study. J. Comp. Neurol. 451, 301-323.

Suddendorf, T., and Corballis, M. C. (1997). Mental time travel and the evolution of the human mind. Genet. Soc. Gen. Psychol. Monogr. 123, 133-167.

Suzuki, W. A., and Amaral, D. G. (1994a). Topographic organization of the reciprocal connections between the monkey entorhinal cortex and the perirhinal and parahippocampal cortices. J. Neurosci. 14, 1856-1877.

Suzuki, W. A., and Amaral, D. G. (1994b) Perirhinal and parahippocampal cortices of the macaque monkey, cortical afferents. J. Comp. Neurol. 350 497-533.

Suzuki, W. A., Zola-Morgan, S., Squire, L. R., and Amaral, D. G. (1993). Lesions of the perirhinal and parahippocampal cortices in the monkey produce long-lasting memory impairment in the visual and tactual modalities. J. Neurosci. 13, 2430-2451.

Tian, B., Reser, D., Durham, A., Kustov, A., and Rauschecker, J. P. (2001) Functional specialization in rhesus monkey auditory cortex. Science 292, 290-293.

Tranel, D., Brady, D. R., Van Hoesen, G. W., and Damasio, A. R. (1988). Parahippocampal projections to posterior auditory association cortex (area Tpt) in old-world monkeys. Exp. Brain Res. 70, 406-416.

Trojanowski, J. Q., and Jacobson, S. (1975). A combined horseradish peroxidase-autoradiographic investigation of reciprocal connections between superior temporal gyrus and pulvinar in squirrel monkey. Brain Res. $85,347-353$.

Trojanowski, J. Q., and Jacobson, S. (1977). The morphology and laminar distribution of cortico-pulvinar neurons in the rhesus monkey. Exp. Brain Res. 28, 51-62. 
Tulving, E. (2004). Episodic memory, from mind to brain. Rev. Neurol. (Paris) 160, S9-S23.

Van Hoesen, G. W. (1981) "The differential distribution, diversity and sprouting of cortical projections to the amygdala in the rhesus monkey," in The Amygdaloid Complex ed. Y. Ben-Ari (Amsterdam: Elsevier/ North Holland Biomedical Press), 77-90.

Vogt, B. A., and Pandya, D. N. (1987). Cingulate cortex of the rhesus monkey, II. Cortical afferents. J. Comp. Neurol. 262, 271-289.

Vogt,B.A., and Barbas, H. (1988). "Structure and connections of the cingulate vocali- zation region in the rhesus monkey," in The Physiological Control of Mammalian Vocalization, ed. J. D. Newman (New York : Plenum), 203-225.

Von Bonin, G., and Bailey, P. (1947). The Neocortex of Macaca Mulatta. Urbana, Illinois: University of Illinois, Illinois Press.

Witter, M. P., and Amaral, D. G. (1991). Entorhinal cortex of the monkey, V. Projections to the dentate gyrus, hippocampus, and subicular complex. $J$. Comp. Neurol. 307, 437-459.

Witter, M., and Wouterlood, F. (2002). The Parahippocampal Region, Organization and Role in Cognitive Function. Oxford: Oxford University Press.
Wright, A. A. (2007). An experimental analysis of memory processing. J. Exp. Anal. Behav. 88, 405-433.

Yonelinas, A. (2002). The nature of recollection and familiarity. A review of 30 years of research. J. Mem. Lang. 46, 441-517.

Yukie, M. (1995). Neural connections of auditory association cortex with the posterior cingulate cortex in the monkey. Neurosci. Res. 22, 179-187.

Conflict of Interest Statement: The authors declare that the research was conducted in the absence of any commercial or financial relationships that could be construed as a potential conflict of interest.
Received: 01 April 2010; paper pending published: 17 May 2010; accepted: 28 July 2010; published online: 08 October 2010. Citation: Munoz-Lopez MM, MohedanoMoriano $A$ and Insausti $R$ (2010) Anatomical pathways for auditory memory in primates. Front. Neuroanat. 4:129. doi: 10.3389/fnana.2010.00129

Copyright (C) 2010 Munoz-Lopez, Mohedano-Moriano and Insausti. This is an open-access article subject to an exclusive license agreement between the authors and the Frontiers Research Foundation, which permits unrestricted use, distribution, and reproduction in any medium, provided the original authors and source are credited. 